RESEARCH

\title{
Reappraisal of shear wave elastography as a diagnostic tool for identifying thyroid carcinoma
}

\author{
Kristine ZøyIner Swan ${ }^{1,2}$, Steen Joop Bonnema ${ }^{3}$, Marie Louise Jespersen ${ }^{4}$ and Viveque Egsgaard Nielsen ${ }^{2}$ \\ 1'Department of Otorhinolaryngology Head \& Neck Surgery, Aarhus University Hospital, Aarhus N, Denmark \\ ${ }^{2}$ Department of Clinical Medicine, Health, Aarhus University, Aarhus N, Denmark \\ ${ }^{3}$ Department of Endocrinology, Odense University Hospital, Odense C, Denmark \\ ${ }^{4}$ Department of Pathology, Aarhus University Hospital, Aarhus N, Denmark \\ Correspondence should be addressed to K Z Swan: kristineswan@dadlnet.dk
}

\begin{abstract}
Thyroid nodular disease is common, but predicting the risk of malignancy can be difficult. In this prospective study, we aimed to assess the diagnostic accuracy of shear wave elastography (SWE) in predicting thyroid malignancy. Patients with thyroid nodules were enrolled from a surgical tertiary unit. Elasticity index (EI) measured by SWE was registered for seven El outcomes assessing nodular stiffness and heterogeneity. The diagnosis was determined histologically. In total, 329 patients (mean age: $55 \pm 13$ years) with 413 thyroid nodules (mean size: $32 \pm 13 \mathrm{~mm}, 88$ malignant) were enrolled. Values of SWE region of interest (ROI) for malignant and benign nodules were highly overlapping (ranges for SWEROImean: malignant 3-100 kPa; benign 4-182 kPa), and no difference between malignant and benign nodules was found for any other El outcome investigated $(P=0.13-0.96)$. There was no association between $\mathrm{El}$ and the histological diagnosis by receiver operating characteristics analysis (area under the curve: 0.51-0.56). Consequently, defining a cutoff point of El for the prediction of malignancy was not clinically meaningful. Testing our data on previously proposed cut-off points revealed a low accuracy of SWE (56-80\%). By regression analysis, factors affecting El included nodule size $>30 \mathrm{~mm}$, heterogeneous echogenicity, micro- or macrocalcifications and solitary nodule. In conclusion, El, measured by SWE, showed huge overlap between malignant and benign nodules, and low diagnostic accuracy in the prediction of thyroid malignancy. Our study supports that firmness of thyroid nodules, as assessed by SWE, should not be a key feature in the evaluation of such lesions.
\end{abstract}

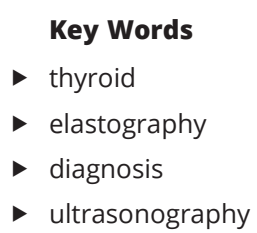

Endocrine Connections (2019) 8, 1195-1205

\section{Introduction}

Thyroid nodular disease is common in many populations, with the majority of the nodules being benign (1). The primary purpose of diagnostic testing is to assess the risk of thyroid carcinoma in these nodules. Although ultrasonography (US) and fine-needle aspiration biopsy (FNAB) are very useful in the evaluation of thyroid nodules, the identification of malignancy remains a challenge. Several US characteristics have been found to be more prevalent in malignant compared with benign thyroid nodules. However, these need to be combined, since no single characteristic can discriminate reliably malignant from benign nodules $(2,3,4)$. Accordingly, several US risk stratification tools have been proposed during the past decades in an attempt to increase the clinical usefulness of US as well as to assist the clinician in deciding when to perform FNAB and thyroid surgery $(3,5,6,7,8,9,10,11)$. 
Despite these efforts, diagnostic thyroid surgery is often necessary in patients with indeterminate or suspicious FNAB (12), putting the patient at risk of possible surgical complications.

US elastography has been proposed as a novel tool to increase the diagnostic value of thyroid US, as an adjuvant to US features obtained by grayscale assessments $(8,13,14$, $15,16,17)$. Various elastographic technologies exist, based on different methods for tissue displacement (e.g. manual compression or acoustic impulses from the transducer) and different elasticity measurements (e.g. qualitative by a color image, semi-quantitative by a ratio, quantitative by a numerical value) (18). Shear wave elastography (SWE), available on the SuperSonic Aixplorer equipment (SuperSonic, Aix-en-Provence, France), uses acoustic impulses from the transducer to measure tissue elasticity quantitatively by an elasticity index (EI), expressed in kilo Pascal $(\mathrm{kPa})$ and qualitatively by a color-coded elasticity map (18). SWE has the potential to differentiate benign from malignant thyroid nodules. However, the optimum EI cut-off point for such a discrimination shows large variations across studies $(26-85 \mathrm{kPa})$, and the EI ranges applying to malignant and benign nodules, respectively, overlap to a great extent $(13,14,15,16,19,20,21,22,23$, $24,25,26)$.

Considering the diverging results, it remains unclear if SWE has a role in the routine work-up of patients with thyroid nodules, when it comes to assessing the risk of cancer in the individual patient. Thus, the objective of the present prospective study was to evaluate the diagnostic properties of SWE in the preoperative management and risk stratification of thyroid nodules in patients referred for thyroid surgery.

\section{Materials and methods}

We conducted a prospective cohort study enrolling patients from the Department of Otorhinolaryngology Head \& Neck Surgery (a tertiary surgical unit), Aarhus University Hospital, Denmark, from January 2014 to February 2016. All patients underwent thyroid surgery, providing histological results of the specimens (100\%). The majority of nodules (83\%) also provided preoperative FNAB results (Table 1). Eligible patients were identified consecutively from the outpatient clinic or the surgical ward according to the inclusion criteria described below. Patients were included during their visit to the department in a nonselective manner. Complete consecutive enrolment was not possible for practical reasons, as all US and SWE data were provided by only two investigators (KZS, VEN). The inclusion criteria were adult patients ( $\geq 18$ years) with one or more thyroid nodules $\geq 10 \mathrm{~mm}$ in the largest dimension, and indication for thyroid surgery providing histological specimens. Patients were excluded if the index nodule was predominately cystic with insufficient solid areas for SWE registration or if SWE registration was not possible $(n=6)$ due to technical limitations of the technology (rim calcifications, no SWE signal) or practical limitations in the department. Patients with multinodular goiter (MNG) had more than one nodule examined for the study, provided these lesions were assessable for SWE imaging and fulfilled the inclusion criteria. Before enrolment in the study, written informed consent was obtained from each participant. The study complies with the Declaration of Helsinki, and it was approved by the Local Ethics Committee of the Central Denmark Region, Denmark, and the Danish Data Protection Agency, and was registered at ClinicalTrials.gov (NCT02150772).

\section{Pathological examination}

The histological diagnosis served as the diagnostic reference standard in all patients, using formalinfixed paraffin-embedded tissue blocks and the WHO classification. FNAB results were available in 305 (93\%) patients. The biopsies were examined by a specialized endocrine pathologist (MLJ, 5 years of experience) and described preoperatively according to the Bethesda system of reporting thyroid cytology (BSRTC) with assignment of a category from 1 to 6 (27).

Table 1 Cytological results for nodules.

\begin{tabular}{|c|c|c|c|}
\hline BSRTC & Distribution, $\boldsymbol{n}(\%)$ & $\begin{array}{c}\text { Malignancy } \\
\text { rate, } \%\end{array}$ & Histological diagnosis \\
\hline No FNAB & 69 (17) & 3 & 1 PTC, 1 met \\
\hline BSRTC 1 & $50(12)$ & 14 & 7 PTC \\
\hline BSRTC 2 & $90(22)$ & 7 & $3 \mathrm{PTC} / 3 \mathrm{miTC}$ \\
\hline BSRTC 3 & $29(7)$ & 10 & 2 PTC, 1 lym \\
\hline BSRTC 4 & $96(23)$ & 25 & 8 PTC/2 miTC, 14 FTC \\
\hline BSRTC 5 & $48(12)$ & 40 & $\begin{array}{l}14 \text { PTC/3 miTC, } 1 \\
\text { FTC, } 1 \text { met }\end{array}$ \\
\hline BSRTC 6 & $30(7)$ & 90 & $\begin{array}{l}22 \text { PTC/1 miTC, } 1 \\
\text { FTC, } 1 \text { MTC, } 2 \text { sar }\end{array}$ \\
\hline Total & $413(100)$ & 21 & \\
\hline
\end{tabular}

BSRTC, Bethesda system of reporting thyroid cytology; FNAB, fine needle aspiration biopsy; FTC, follicular thyroid carcinoma; lym, lymphoma; met, metastasis from renal cell carcinoma; miTC, thyroid micro-carcinoma; MTC, medullary thyroid carcinoma; PTC, papillary thyroid carcinoma; sar, myxofibrosarcoma. 


\section{Equipment and procedure}

Ultrasonography and SWE were performed preoperatively using the SuperSonic Aixplorer and a linear probe (4-15 MHz). In SWE mode, a color-coded elasticity map was generated by converting shear wave speed to an EI expressed in $\mathrm{kPa}$ using Young's modulus (18). The elasticity scale was set at $0-100 \mathrm{kPa}$. The examinations were performed by one research fellow and one staff specialist in otorhinolaryngology (KZS, VEN), with 18 months and 12 years of experience with US, respectively, and both with 6 months of experience with SWE. During this 6-month period, weekly SWE training sessions were performed. Methodological results regarding observer agreement have been reported previously in a subset of patients $(n=72)(28)$.

During US and SWE examinations, the patient was lying in a supine position with the neck slightly extended. US grayscale examination of the index nodule was performed before SWE acquisition, with the registration of pre-specified US features used for malignancy risk stratification. The index nodule was examined systematically in both US and SWE mode before selecting the plane for SWE acquisition. By avoiding artifacts, assessed by both B- and SWE mode, the stiffest area of the nodule was identified according to the SWE color scale. For SWE acquisition, the probe was held still in the transverse plane for more than $3 \mathrm{~s}$ and until the color codes had stabilized. Precompression was avoided. Each SWE acquisition was repeated consecutively three times by each investigator by removal and replacement of the probe within 1-2 min. The results of intra-observer reliability have been published (28). The investigators were blinded to the quantitative EI measurements (not yet obtained) and, due to the prospective nature of the study, the histological diagnosis of the nodule. The investigators were not blinded to clinical characteristics, US grayscale features, supplementary tests (e.g. ${ }^{99 \mathrm{~m}}$ Tc-scintigraphy), or FNAB results, in order to conduct the study in a clinically viable setting.

Patient characteristics and supplementary data were collected from patient charts including demographics, clinical risk-markers for thyroid malignancy, smoking status, body mass index, thyroid function tests, anti-TPO antibodies, treatment with thyroid hormone supplements, previous radioiodine (RAI) therapy, ${ }^{99 m}$ Tc-scintigraphy (if available), positron emission tomography (if available), FNAB results according to the BSRTC (27) and indication for thyroid surgery.

\section{Elasticity measurements}

After acquisition of all three SWE images, the same investigator placed color-guided size adjustable regions of interest (ROI) in each of the frozen SWE images to assess EI, according to predefined criteria, as previously described (28) (Fig. 1). (1) SWE-ROI: $3 \mathrm{~mm}$ Q-box ${ }^{\mathrm{RM}}$ including the stiffest area of the nodule, (2) SWE-stiff: Q-box ${ }^{\mathrm{RM}}$ of variable size including only the stiffest area of the nodule, (3) SWE-Center: $10 \mathrm{~mm}^{\mathrm{Q}-\mathrm{box}^{\mathrm{RM}}}$ in the center of the nodule surrounding the stiffest area. Stiff areas were identified from the color-coded elasticity map, as indicated by red, yellow or green color (decreasing stiffness) being distinguishable from the soft blue-colored areas (Fig. 1). For each color-coded Q-box ${ }^{\mathrm{RM}}$ the system's software generated a quantitative mean, minimum, maximum and a standard deviation (s.D.) value of EI. The EI outcomes investigated were chosen before initiation of the study from criteria of clinical relevance guided by results from the literature published at the time of study planning (19, $20,21,22,23,29)$, and novel outcomes assessing elastic heterogeneity were added. SWE-ROImean and -max, SWE-Stiffmean and -max, and SWE-Centermean provided estimates of elasticity around the stiffest area of the nodule. SWE-ROInn ratio and SWE-CenterSD were estimates of elastic heterogeneity within the nodule. When selecting the region for elasticity measurements within the nodule, the following features were avoided: macrocalcifications, cystic areas, vertical artifacts, structure interface artifacts,

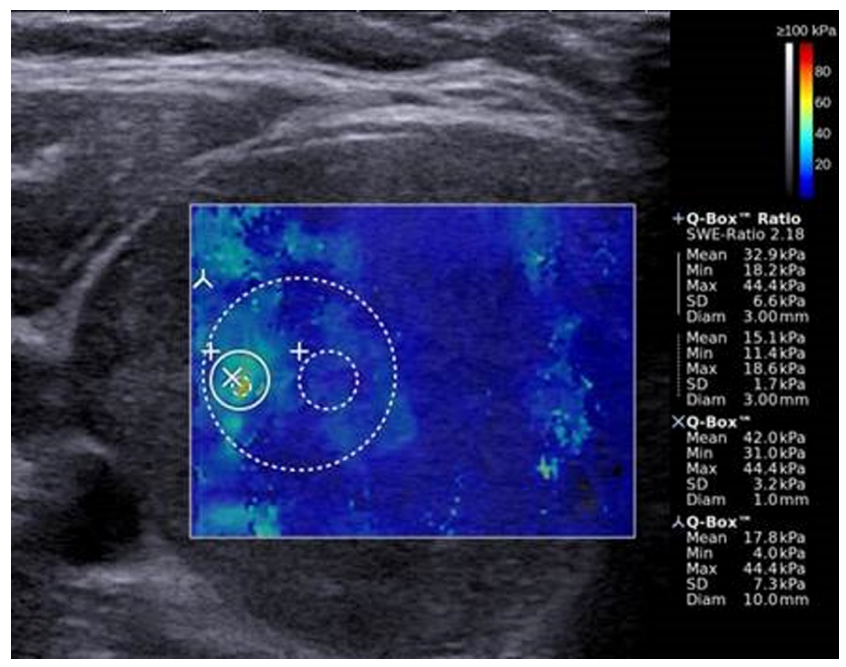

Figure 1

SWE image depicting the ROIs used for El measurements. Color-coded elasticity map overlying the B-mode US image. Soft areas with a low El are colored blue, and changes to green, yellow and red with higher El and increasing stiffness. To the right, the elasticity scale (0-100 kPa, top) and the El measurements for the predefined ROIs (bottom) are shown.

This work is licensed under a Creative Commons Attribution-NonCommercial-NoDerivatives 4.0 Internationab kicense.ifica com at $04 / 26 / 2023$ 01:15:34PM 
areas with signs of pre-compression and areas with poor or no SWE signal (no color). After the inclusion period, both investigators retrospectively re-assessed all images to ensure that no ROIs were placed within artifacts.

Qualitative elasticity assessment was conducted by the investigator performing the SWE examination and using a modification of the three-point scale proposed by Rago et al. (30). This rating tool was developed for qualitative assessment of strain elastography, which uses manual compression as external force and depicts stiff areas in blue color. The technology of SWE is fundamentally different from that of strain elastography. However, for the present study, the difference in color coding was taken into account, so that the Rago scale could be adopted for a qualitative assessment based on SWE images. Score 1: elasticity in the entire or in a large part of the nodule corresponding to a predominately soft nodule (blue); score 2: elasticity only in the peripheral part of the nodule corresponding to intermediate stiffness (blue and green/ yellow); score 3: no elasticity in the nodule corresponding to a predominately or completely stiff nodule (yellow and red). Score 1 represents a benign nodule, while scores 2 and 3 represent a nodule suspicious for malignancy (30).

\section{Grayscale US features}

Patients were categorized into three groups according to US grayscale features indicative of malignancy, by applying a modification of the French thyroid imaging reporting and data system (TIRADS) (8). Suspicious US features were hypoechogenicity (compared with normal thyroid parenchyma and thus pooling mild and marked hypoechoic patterns), microcalcifications, irregular margins and taller-than-wide shape. Low-risk nodules were those without any suspicious US feature (TIRADS 2-3); intermediate risk nodules had 1-2 features (TIRADS 4A-4B), while high-risk nodules had 3-4 suspicious features present and/or suspicious lymph nodes at neck US examination (TIRADS 5).

\section{Statistical analysis}

Continuous variables are presented as mean and S.D., or median, range and interquartile range (IQR). Categorical variables are presented as numbers and percentages. For all EI outcomes, the mean of three repeated measurements was used. Comparisons between groups were performed for continuous data with normal distribution using Student's $t$-test, while Mann-Whitney rank-sum test was used for data with non-normality. For dichotomous data, chi-squared test was used, while Fisher's exact test was used for analyses including small groups $(n<5)$. For EI data, the $t$-test was performed on a logarithmic transformation due to nonnormality of the data. Receiver-operating characteristic (ROC) analysis was conducted to assess the association between EI and the histological diagnosis, using area under the curve (AUC) estimates. Sensitivity, specificity, positive predictive value (PPV), negative predictive value (NPV) and accuracy were calculated for different cut-off points, as proposed in previous studies of thyroid SWE $(13,14,15,21$, $22,23,24,26)$. Univariate and multivariate linear regression analyses were performed on a logarithmic transformation of the EI data, with the $3 \mathrm{~mm}$ SWE-ROImean as the dependent variable. The independent variables included clinically relevant continuous and categorical parameters, which were assumed to influence tissue elasticity, as listed in Table 5. According to the sample size, the number of explanatory variables were reduced in the multivariate analysis. The patient allocation number was included as a cluster variable to account for multinodularity. $P$ value $<0.05$ indicated statistical significance. The statistical software used was Stata 13 (Metrika Consulting AB, Stockholm, Sweden) and Excel 2010 (Microsoft).

Calculation of the targeted sample size was based on an expected difference in EI between malignant and benign nodules of $15 \mathrm{kPa}$, with a common SD of $32 \mathrm{kPa}$, a power of $95 \%$ and a significance level of 0.05 . Expecting a ratio of four between malignant and benign nodules, 74 malignant and 296 benign nodules, respectively, needed to be included in the study.

\section{Results}

\section{Participants}

In total, 329 patients (male/female: $78(24 \%) / 251(76 \%)$ ) harboring 413 thyroid nodules were included. The flow of participants through the study is shown in Fig. 2. The mean age of included patients was $55 \pm 13$ years (range: 21-89), and patients with benign nodular disease were slightly but significantly older ( $56 \pm 12$ years), as compared with thyroid cancer patients $(52 \pm 16)(P=0.03)$. A solitary nodule was found in 149 patients and MNG in 180 patients. The indication for surgery was diagnostic (BSRTC $1,3,4)$ in $155(47 \%)$ patients, suspicion of malignancy (BSRTC 5,6$)$ in $88(27 \%)$ patients and benign indication due to compressive or cosmetic symptoms (BSRTC 2) in $86(26 \%)$ patients. The FNAB results according to the BSRTC is shown in Table 1. According to biochemical testing $270(82 \%)$ patients were euthyroid, 2 (0.01\%) 


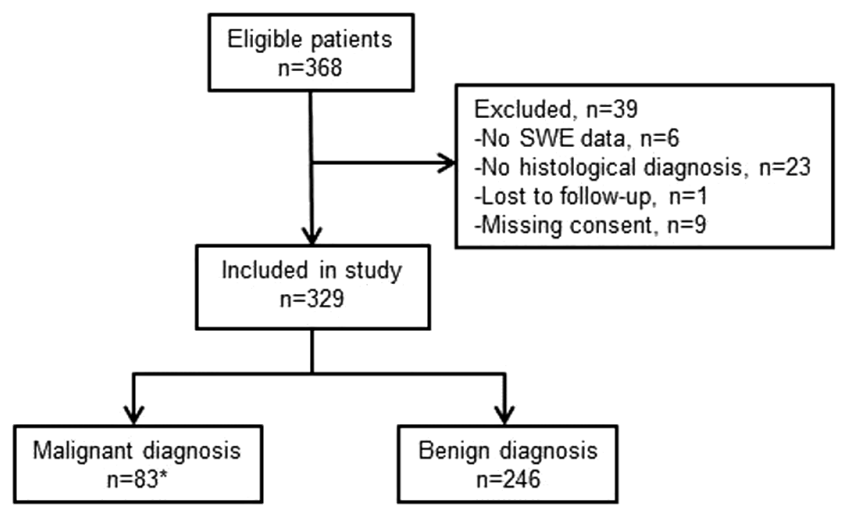

Figure 2

Flow of patients. *Including seven patients with thyroid micro-carcinoma.

were hypothyroid, 14 (4\%) were hyperthyroid, 13 were subclinical hyperthyroid (4\%) and 51 (16\%) patients had positive anti-TPO antibodies. Seventeen patients received thyroid hormone supplementation. Of the 413 nodules included for evaluation, 325 were benign (79\%) and 88 (21\%) malignant, here among 57 papillary thyroid carcinoma (PTC), 16 follicular thyroid carcinoma (FTC), one medullary thyroid carcinoma (MTC), nine thyroid microcarcinoma (miTC) and five other malignancies (lymphoma $(n=1)$; renal cell carcinoma $(n=2)$, myxofibrosarcoma $(n=2$ in one patient)). The median time interval between SWE and surgery was 6 days (IQR: 0-10 days).

Of the 329 included patients, two did not provide EI data but only qualitative data due to large artifacts. EI measurements for the $10 \mathrm{~mm}$ ROI (SWE-Centermean, SWE-CenterSD) were missing in 42 patients either due to artifacts $(n=5)$ or the transverse plane being $<10 \mathrm{~mm}$, which occurred when this was not the largest dimension $(n=37)$. Nine micro-carcinomas (miTCs) (tumor diameter $<10 \mathrm{~mm}$ ) within an otherwise benign nodule in seven patients were excluded from the comparative analyses of benign and malignant nodules, due to uncertainty of the diagnosis in the measured region.

Table 2 Ultrasonographic features comparing malignant and benign nodules.

\begin{tabular}{|c|c|c|c|}
\hline & Malignant & Benign & \\
\hline Ultrasonographic features & $n=79^{\mathrm{a}}$ & $n=325$ & $P$ value \\
\hline Nodule size, $\mathrm{mm}$ (mean \pm S.D.) & $33 \pm 15$ & $32 \pm 13$ & 0.88 \\
\hline Skin-nodule distance, $\mathrm{mm}$ (mean \pm S.D.) & $18 \pm 5$ & $19 \pm 5$ & 0.25 \\
\hline \multicolumn{4}{|l|}{ Nodularity, $n(\%)$} \\
\hline Solitary nodule & $38(48)$ & $107(33)$ & \multirow[t]{2}{*}{$0.01^{b}$} \\
\hline Multinodular goiter & $41(52)$ & $217(67)$ & \\
\hline \multicolumn{4}{|l|}{ Structure, $n(\%)$} \\
\hline Cystic-solid & $22(28)$ & $165(51)$ & \multirow[t]{2}{*}{$<0.01^{c}$} \\
\hline Solid & $57(72)$ & $160(49)$ & \\
\hline \multicolumn{4}{|l|}{ Echogenicity, $n(\%)$} \\
\hline Hypoechoic & $68(86)$ & $185(57)$ & \multirow[t]{3}{*}{$<0.01^{d}$} \\
\hline Isoechoic & $6(8)$ & $91(28)$ & \\
\hline Hyperechoic & $5(6)$ & $49(15)$ & \\
\hline Heterogeneous echogenicity, $n$ (\%) & $64(81)$ & $223(68)$ & 0.03 \\
\hline Microcalcifications, $n(\%)$ & $51(65)$ & $150(46)$ & 0.01 \\
\hline Macrocalcifications, $n(\%)$ & $12(15)$ & $41(13)$ & 0.54 \\
\hline Taller-than-wide shape, $n(\%)$ & $12(15)$ & $37(11)$ & 0.35 \\
\hline \multicolumn{4}{|l|}{ Borders, $n(\%)$} \\
\hline Halo present & $25(32)$ & $139(43)$ & \multirow[t]{2}{*}{$0.07^{e}$} \\
\hline Partial halo & $3(4)$ & $31(10)$ & \\
\hline Irregular margins, $n(\%)$ & $37(47)$ & $103(32)$ & $0.01^{f}$ \\
\hline \multicolumn{4}{|l|}{ Doppler flow, $n(\%)$} \\
\hline Perinodular & $25(32)$ & $148(45)$ & \multirow[t]{4}{*}{$0.03^{g}$} \\
\hline Central & $11(14)$ & $31(10)$ & \\
\hline Equal flow ${ }^{f}$ & $38(48)$ & $113(35)$ & \\
\hline No flow & $5(6)$ & $33(10)$ & \\
\hline TIRADS $2-3^{h}$ & $8(10)$ & $71(90)$ & 0.02 \\
\hline TIRADS 4-5 & $71(22)$ & $250(78)$ & \\
\hline Poor SWE signal, $n(\%)$ & $23(29)$ & $59(18)$ & 0.03 \\
\hline
\end{tabular}

TIRADS, thyroid imaging reporting and data system.

aExcluding nine thyroid micro-carcinoma. ${ }^{b}$ Comparison of solitary nodules vs multinodular goiter in malignant and benign nodules. ${ }^{\circ}$ Comparison of cystic-solid vs solid structure in malignant and benign nodules. ${ }^{\mathrm{d} C o m p a r i s o n}$ of hypoechoic vs non-hypoechoic (iso- and hyperechoic). ${ }^{\mathrm{e} C o m p a r i s o n}$ of complete halo vs no complete halo. ${ }^{\mathrm{f} C} \mathrm{Cmparison}$ of irregular vs regular margins. ${ }^{\mathrm{B}} \mathrm{Comparison}$ of perinodular vs non-periondular flow (central, equal and no flow) in malignant and benign nodules. ${ }^{\text {h}}$ Four nodules did not provide TIRADS score.

https://ec.bioscientifica.com https://doi.org/10.1530/EC-19-0324 (c) 2019 The authors Published by Bioscientifica Ltd

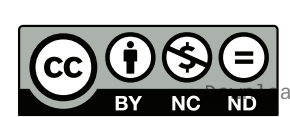

This work is licensed under a Creative Commons Attribution-NonCommercial-NoDerivatives 4.0 Internationab bicense.ifica . com at 04/26/2023 01:15:34PM 
Table 3 El for the selected El outcomes

\begin{tabular}{lcc}
\hline El outcome, kPa & & Malignant $^{\mathbf{a}}$ \\
\cline { 1 - 2 } Median (range), IQR & $(n=77)$ \\
\hline SWE-ROImean & $27(3-100)$ \\
SWE-ROImax & $16-41$ \\
SWE-ROInn ratio & $40(11-148)$ \\
SWE-Stiffmean & $24-62$ \\
SWE-Stiffmax & $2.4(1.0-15.1)$ \\
& $2.0-3.6$ \\
SWE-Centermean & \\
& $33(4-116)$ \\
SWE-CenterSD & $19-48$ \\
& $39(11-148)$ \\
& $24-58$ \\
& $17(4-51)$ \\
& $12-25$ \\
& $8.1(1.5-31.6)$ \\
\end{tabular}

\begin{tabular}{c}
\hline Benign $^{\mathbf{a}}$ \\
\hline$(n=324)$ \\
\hline $28(4-182)$ \\
$19-37$ \\
$39(6-242)$ \\
$28-50$ \\
$2.4(1.1-27.6)$ \\
$1.9-3.1$ \\
$32(4-192)$ \\
$23-42$ \\
$38(6-242)$ \\
$27-49$ \\
$16(4-88)$ \\
$12-22$ \\
$7.1(1.3-56.5)$ \\
$5.0-9.6$
\end{tabular}

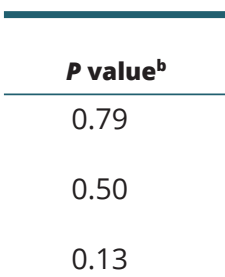

\begin{tabular}{c}
\hline ROc \\
\hline AUC $(95 \% \mathrm{Cl})$ \\
\hline $0.51(0.42-0.59)$ \\
$0.53(0.44-0.61)$
\end{tabular}

0.96

$0.55(0.48-0.62)$

0.52

$0.52(0.44-0.60)$

0.61

$0.52(0.44-0.61)$

0.16

$0.52(0.44-0.61)$

$0.56(0.48-0.64)$

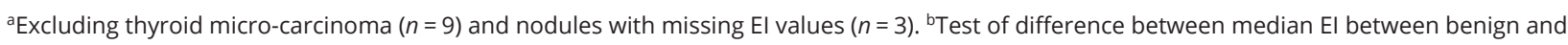
malignant nodules. 'Receiver-operating characteristic (ROC) analysis area under the curve (AUC) for the prediction of malignancy. An AUC of 0.5 reflects that the optimal cut-off value yields an even chance of a test being true or false positive, while a value of 1.0 reflects that the cut-off value yields $100 \%$ sensitivity and specificity. ${ }^{\mathrm{d}} 49$ nodules did not provide data for the $10 \mathrm{~mm}$ center Q-box.

$\mathrm{El}$, elasticity index; IQR, interquartile range; kPa, kilo Pascal.

\section{Test results}

\section{Ultrasound characteristics}

US characteristics of included patients are presented in Table 2. US features associated with an increased risk of malignancy were solitary nodule, solid structure, hypo-echogenicity, heterogeneous echo pattern, microcalcifications, irregular margins, increased central vascularization, TIRADS score and poor SWE signal. When combining signs of high suspicion of malignancy, that is TIRADS 4-5, US reached a sensitivity of $90 \%$, specificity of $22 \%$, PPV of $22 \%$, NPV of $90 \%$ and an accuracy of $36 \%$.

\section{Elasticity index}

No difference in any EI outcome - applying to nodule stiffness or heterogeneity - was found between benign and malignant nodules (Table 3). In fact, the EI parameters were almost identical for all outcomes, and the ranges for benign and malignant nodules, respectively, were hugely overlapping (Table 3 ). The majority of nodules in all histological groups had an EI between 10 and $50 \mathrm{kPa}$ (Fig. 3). By ROC analysis, no association was found between EI and the histological diagnosis, reflected by ROC AUC values in the range $0.51-0.56$ for all EI outcomes (Table 3), whether or not non-PTC cancers were excluded. Similar ambiguous results were found when performing the EI analyses in subgroups according to BSRTC category (indeterminate cytology: BSRTC 3-5 or BSRTC 4), intermediate TIRADS category, structure (solid only), echogenicity (hypoechoic or heterogeneous echogenicity) or vascularity (perinodular flow). However, there was a trend toward lower EI in the malignant group for the subgroups including intermediate TIRADS category or BSRTC 4 nodules only. Analyzing the maximum EI value of the three repeated measurements rather than the mean EI value did not affect the results, nor did the exclusion of one outlier with a histologically benign nodule with a high EI of $182 \mathrm{kPa}$ for SWE-ROImean (data not shown).

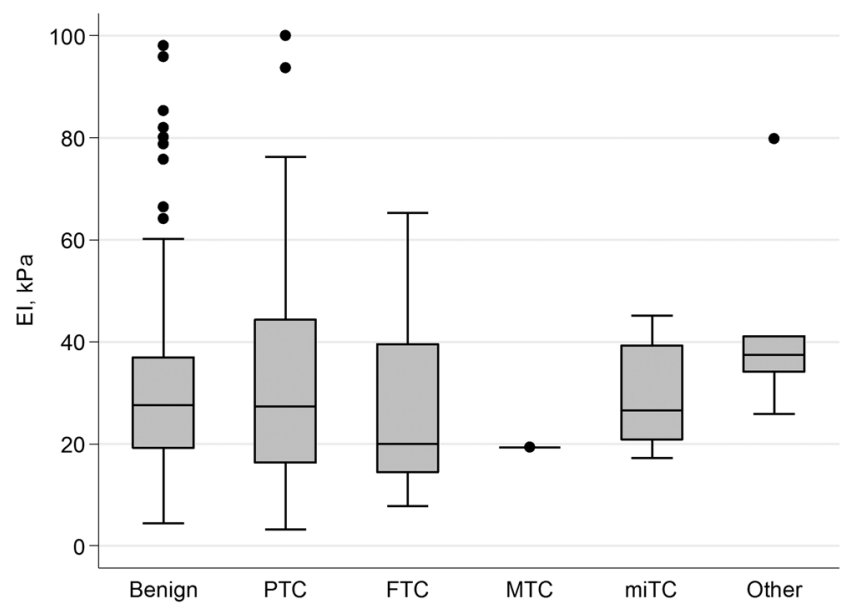

Figure 3

Plot for SWE-ROImean specified by histological diagnosis. Box-andwhisker plot: The boxes display the interquartile range (IQR) and the median, while the whiskers display 1.5 times the IQR. Outliers beyond the whiskers are marked with individual dots. Elasticity index (El); kilo Pascal (kPa); benign, $n=325$; papillary thyroid carcinoma (PTC), $n=57$; follicular thyroid carcinoma (FTC), $n=16$; medullary thyroid carcinoma (MTC), $n=1$; thyroid micro-carcinoma (miTC), $n=9$. Other: lymphoma $(n=1)$, renal cell carcinoma metastasis $(n=2)$, myxofibrosarcoma ( $n=2$ in one patient). The one outlier in the benign group is not shown $(\mathrm{El}=182 \mathrm{kPa})$. 
Table 4 SWE-ROImean tested on cut-off points proposed in previous studies.

\begin{tabular}{|c|c|c|c|c|c|c|}
\hline \multirow[b]{3}{*}{ Cut-off point ${ }^{a}$} & \multirow{3}{*}{$\begin{array}{c}\begin{array}{c}\text { Nodules in previous } \\
\text { study }\end{array} \\
n \text { (malignant, \%) }\end{array}$} & \multicolumn{5}{|c|}{ Test of present data on cut-off points proposed in previous studies } \\
\hline & & \multicolumn{5}{|c|}{ Estimates, \% $(95 \% \mathrm{Cl})$} \\
\hline & & Sensitivity & Specificity & PPV & NPV & Accuracy \\
\hline $30 \mathrm{kPa}(26)$ & $169(30)$ & $46(34-57)$ & $58(53-64)$ & $21(15-27)$ & $82(77-87)$ & $56(51-61)$ \\
\hline 31 kPa (15) & $313(62)$ & $46(34-57)$ & $61(56-66)$ & $22(15-28)$ & $83(78-87)$ & $58(53-63)$ \\
\hline $34 \mathrm{kPa}^{\mathrm{b}}(24)$ & $137(66)$ & $38(27-48)$ & $69(64-74)$ & $22(15-30)$ & $82(78-87)$ & $63(58-68)$ \\
\hline $39 \mathrm{kPa}(13)$ & $331(31)$ & $26(16-36)$ & $80(75-84)$ & $23(14-32)$ & $82(78-86)$ & $69(65-74)$ \\
\hline 42 kPa (23) & $62(27)$ & $23(14-33)$ & $86(82-90)$ & 27 (17-38) & $83(80-87)$ & 75 (70-79) \\
\hline $49 \mathrm{kPa}^{\mathrm{c}}(22)$ & $393(6)$ & $17(9-25)$ & $93(90-96)$ & $36(20-52)$ & $83(79-86)$ & 78 (74-82) \\
\hline 62 kPa (21) & $99(21)$ & $9(3-16)$ & 97 (95-99) & $41(18-65)$ & $82(78-86)$ & 80 (76-84) \\
\hline 85 kPa (14) & $476(80)$ & $3(-1$ to 6$)$ & $99(98-100)$ & $33(-4$ to 71$)$ & 81 (77-85) & $80(76-84)$ \\
\hline Rago 2-3 (29) & $195(20)$ & $33(23-43)$ & $75(70-80)$ & $24(16-32)$ & $82(78-87)$ & $67(62-71)$ \\
\hline
\end{tabular}

aCut-off points proposed in previous studies were selected for El outcomes most similar to the definition of SWE-ROImean. ${ }^{\mathrm{b}}$ Only nodules $<10 \mathrm{~mm}$. ${ }^{\mathrm{C} T h e}$ cut-off point with the highest sum of sensitivity and specificity was selected.

$\mathrm{kPa}$, kilo pascals; NPV, negative predictive value; PPV, positive predictive value.

Additionally, we analyzed the diagnostic value of SWE-ROImean obtained in the present study by applying cut-off points proposed by other authors $(13,14,15,21$, $22,23,24,26)$, as shown in Table 4 . With increasing cutoff point, specificity increased while sensitivity decreased. On the contrary, NPVs were stable between 81 and $83 \%$ irrespective of cut-off point.

\section{Influence of other characteristics}

By univariate linear regression analysis, a range of variables with potential impact on elasticity was tested (Table 5). Nodule size $>30 \mathrm{~mm}$, heterogeneous echogenicity and micro- or macrocalcifications within the index nodule were all positively associated with EI. The presence of a solitary nodule was negatively associated with EI. By multivariate regression analysis, only nodule size $>30 \mathrm{~mm}$ remained statistically significant. Both by univariate and multivariate analysis, FNAB performed prior to SWE did not affect EI measurements $(P=0.64-0.81)$.

\section{Qualitative assessment of SWE}

When assessing the color images qualitatively, the nodules were either homogeneous with low stiffness (blue) or heterogeneous showing a background of low stiffness (blue) with areas of higher stiffness (yellow to red). No nodules were completely stiff (red only). When applying the qualitative Rago scale, 297 nodules were classified as Rago 1, 87 as Rago 2 and 20 as Rago 3. Of the benign nodules, 244 (75\%) were classified as Rago 1, while 26 (33\%) of the malignant nodules (excluding miTC) belonged to the Rago 2-3 categories ( $\mathrm{chi}^{2}, P=0.15$ ). The diagnostic accuracy of the Rago scale applied on our data is shown in Table 4. Including only PTC in the malignant group did not change the results (data not shown).

\section{Discussion}

This large prospective study found no difference in EI, measured by SWE, between malignant and benign thyroid nodules, nor was there any association between EI and the diagnosis by ROC analysis. Similar findings were seen in all subgroups investigated, here among nodules with indeterminate cytology, and if only patients with PTC were included in the cancer group. Furthermore, when applying previously proposed EI cut-off points to our cohort, the diagnostic performance was suboptimal, which goes for both qualitative and quantitative elasticity parameters. In comparison with conventional US features, SWE showed higher specificity while grayscale features exploited higher sensitivity. In accordance with previous studies $(13,20,31)$, EI was related to nodule size $(>30 \mathrm{~mm})$, micro- or macrocalcifications, presence of a solitary nodule and - as a novel finding - to heterogeneous echogenicity.

Thyroid nodular SWE has been evaluated in a number of studies during the past years $(13,14,16,19,20,21$, $22,23,24,25,26)$. Although results have been promising, the clinical applicability has been questionable, probably due to inconsistencies in methodology and differences in population characteristics. One hindrance for a widespread use of thyroid SWE is the lack of consensus regarding the optimum EI outcome and corresponding cut-off level $(13,14,15,16,20,21,22,23,24,25,26,28)$. An observation being unanimously reported is the huge overlap in EI intervals for malignant and benign nodules, respectively $(13,15,16,20,21,23,24,25)$, resulting in suboptimal values of sensitivity and specificity. Furthermore, proposed EI cut-off points for differentiating malignant and benign nodules vary across studies, which lead to misclassification in a considerable number of cases, as pointed out by our study.

This work is licensed under a Creative Commons Attribution-NonCommercial-NoDerivatives 4.0 Internationab ticense.ifica com at $04 / 26 / 2023$ 01:15:34PM 
Table 5 Impact of clinical and ultrasound features on SWE-ROImean.

\begin{tabular}{l}
\hline Independent variable \\
\hline Age \\
Female gender \\
Previous RAl therapy \\
Anti-TPO antibodies level ${ }^{b}$ \\
Size $>30$ mm $^{c}$ \\
Isthmic location \\
Previous FNAB \\
FNAB $<30$ days prior to SWE \\
Malignant histologye \\
Ultrasound features \\
Heterogenicity \\
Hypoechogenicity \\
Microcalcifications \\
Macrocalcifications \\
Poor SWE signal \\
Solitary nodule \\
Solid composition \\
Skin-nodule distance \\
TIRADS group
\end{tabular}

\begin{tabular}{c}
\hline \multicolumn{1}{c}{ Univariate analysis } \\
\hline Ratio $(95 \% \mathrm{Cl})$ \\
\hline $1.00(0.99-1.01)$ \\
$1.02(0.90-1.15)$ \\
$1.02(0.79-1.31)$ \\
$1.00(0.99-1.00)$ \\
$1.16(1.04-1.29)$ \\
$1.09(0.95-1.24)$ \\
$0.99(0.89-1.09)$ \\
$1.04(0.88-1.22)$ \\
$0.99(0.85-1.15)$ \\
\\
$1.19(1.06-1.34)$ \\
$1.04(0.93-1.16)$ \\
$1.17(1.06-1.30)$ \\
$1.25(1.06-1.47)$ \\
$0.95(0.80-1.13)$ \\
$0.86(0.77-0.96)$ \\
$0.91(0.82-1.02)$ \\
$0.99(0.98-1.00)$ \\
$1.07(0.98-1.17)$
\end{tabular}

\begin{tabular}{cc}
\hline sis & \\
\hline 0.48 \\
0.76 \\
0.88 \\
0.23 \\
0.01 \\
0.21 \\
0.81 \\
0.64 \\
0.91 \\
\\
0.01 \\
0.49 \\
0.01 \\
0.01 \\
0.55 \\
0.01 \\
0.09 \\
0.27 \\
0.11
\end{tabular}

\begin{tabular}{ccc}
\hline \multicolumn{2}{c}{ Multivariate analysisg } \\
\hline Ratio $(95 \% \mathrm{Cl})$ & & $P$ value \\
\cline { 1 - 1 } $1.00(0.99-1.01)$ & & 0.25 \\
$0.96(0.84-1.09)$ & & 0.53 \\
& & \\
$1.00(0.99-1.00)$ & & 0.22 \\
$1.18(1.05-1.33)$ & & 0.01 \\
$1.08(0.93-1.26)$ & & 0.32 \\
$1.02(0.91-1.14)$ & & 0.74 \\
& & \\
& & \\
$1.10(0.96-1.26)$ & & 0.18 \\
$0.95(0.84-1.08)$ & & 0.42 \\
$1.12(0.99-1.26)$ & & 0.06 \\
$1.12(0.92-1.37)$ & 0.27 \\
$0.92(0.77-1.10)$ & 0.34 \\
$0.92(0.81-1.04)$ & 0.20 \\
$1.04(0.92-1.18)$ & 0.50 \\
& \\
&
\end{tabular}

Dependent variable in regression analysis: logarithmic transformation of SWE-ROImean.

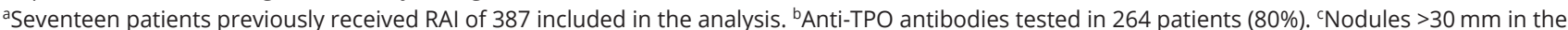

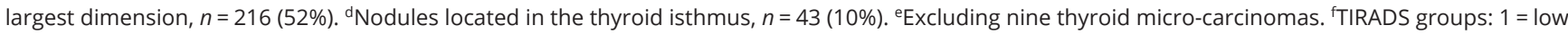
risk; 2 = intermediate risk; 3 = high risk. ${ }^{3}$ According to the sample size, a subset of explanatory variables were excluded from the multivariate analysis. The variables assumed to influence elasticity measurements were chosen before data analysis. All explanatory variables were included in one multivariate regression analysis.

FNAB, fine-needle aspiration biopsy; RAI, radioiodine ablation; SWE, shear wave elastography; TIRADS, thyroid imaging reporting and data system.

Results from recent studies challenge the clinical applicability of thyroid SWE even more. In a smaller study, but in line with our results, Bardet et al. (32) found no difference in EI between 110 benign and 21 malignant nodules with indeterminate cytology. Moreover, a recent meta-analysis - including 2851 nodules from 14 studies found suboptimal diagnostic accuracy of thyroid SWE, with a significant heterogeneity between studies and a pooled sensitivity and specificity of 0.66 and 0.78 , respectively (33). These results contrast those from previous metaanalyses $(34,35,36)$ which, however, included a smaller number of nodules and used sensitivity and specificity estimates applying to different cut-off points $(33,34,35$, 36). This discrepancy emphasizes that the performance of thyroid SWE may have been overestimated in the earlier explorative studies.

Methodological issues and heterogeneity between the studies - compromising the generalizability of thyroid SWE - may explain the inconsistent results. First, the malignancy rate as well as prevalence of PTC affects the EI results. PTC show higher EI, compared with other thyroid malignancies and benign nodules $(23,32)$, and the best diagnostic performance of SWE seems to be obtained when comparing benign nodules with PTC only $(13,14,15,16$,
$19,20,21,22,23,24,25,26)$. However, the heterogeneous elasticity pattern of PTC - and of benign nodules as well may be a drawback in this context $(28,37,38)$. Second, the pre-setting of the elasticity scale is of crucial importance. Thus, a higher scale setting of $0-180 \mathrm{kPa}$ seems to increase the EI cut-off points $(27-85 \mathrm{kPa})(13,14,15,16,21,22,23)$ because larger EI differences are required for similar colorchanges, as compared with the recommended $0-100 \mathrm{kPa}$ scale (4) (cut-off points: $30-34 \mathrm{kPa})(24,26)$. The relatively low sensitivity of detectable color changes in the elasticity map, may also explain the high variability of EI measurements in nodules that appear qualitatively similar in their elasticity mapping. This may explain the slight discordant results of the SWE-ROImax and SWE-Stiffmax, although these ROIs are almost identically defined. Third, the pre-compression level affects the stiffness of both normal thyroid tissue, and benign and malignant nodules $(37,39,40)$. Increasing the pre-compression leads to a more favorable ratio between benign and malignant nodules (40), but may also increase the variation of EI measurements (40). Currently, no method for quantification of the pre-compression level is available, although highly needed. Finally, nodule size affects EI measurements according to three studies $(13,24,25)$, https://ec.bioscientifica.com https://doi.org/10.1530/EC-19-0324 (c) 2019 The authors Published by Bioscientifica Ltd
This work is licensed under a Creative Commons Attribution-NonCommercial-NoDerivatives 4.0 Internationab sicense.ifica . com at 04/26/2023 01:15:34PM 
which showed that stiffness was lower in nodules smaller than $10 \mathrm{~mm}$ compared with larger nodules. We also found such influence of dimension, although at a nodule size of $30 \mathrm{~mm}$. In consequence, different cut-off points for the EI parameters should be applied, depending on nodule size, but this issue seems to be widely overlooked.

Ultrasound-based assessment of tissue elasticity relies on simplified models related to the response to applied external forces, thus measuring elasticity indirectly (18). The models assume that the investigated tissue responds with linearity and homogeneity $(18,39)$. However, thyroid nodules exhibit the opposite properties that is nonlinearity and heterogeneity, due to composite of cell dense areas, fibrosis, calcifications, adipose tissue and cystic areas $(18,37,38)$. This may lead to significant artifacts in both benign and malignant nodules, which may explain the huge overlap of elasticity measurements, as found in the present and previous studies $(21,23)$. Further, the interpretation of artifacts, due to structure interfaces and different responses to increasing pre-compression levels $(40,41)$, emphasizes the importance of a standardized and systematic evaluation of the qualitative elasticity maps, in order to perform reliable quantitative elasticity measurements. Currently, the acquisition process and interpretation of artifacts need standardization, and may be the explanation for the diverging results.

SWE seems promising for the evaluation of tumors in other organs than the thyroid gland, like the breast (42) and the prostate (43) although results have been inconsistent. On the other hand, SWE is less suitable for polycystic ovaries (44), which in line with thyroid nodules exhibit heterogeneous US patterns.

Our study has several strengths. We investigated prospectively one of the largest cohorts by thyroid SWE, and with confirmed diagnosis in all patients. A high number of benign thyroid nodules, as well as a clinically viable proportion of malignant nodules were included. Furthermore, patients with cytological samples in the indeterminate BSRTC 3-5 categories represented almost half of the cohort (42\%) and were included in additional subgroups analyses. These individuals, who are most difficult to diagnose without surgery, were excluded from previous studies without histological confirmation of the diagnosis $(13,14,21,23,24)$. Thus, the advantages of having all cases fully histologically characterized outweigh the potential drawback of investigating a selected surgical cohort. The EI measurements were found to be unaffected by the preceding FNAB (performed in most patients), neither regarding the sampling per se nor the time interval between the two procedures. This is an important issue since FNAB potentially might result in hematoma or fibrosis of the thyroid nodule, with obvious consequences for tissue elasticity (38).

The diagnostic properties of the TIRADS system from 2013 (8), employed in the present study can easily be extrapolated to the more recent EU-TIRADS (11), since the combined categories 4-5 are similar in the two classification systems. Our study finds lower diagnostic accuracy of the TIRADS compared with previous findings (8), which most likely is explained by the higher rate of malignancy in our surgical cohort. This emphasizes that the TIRADS primarily is designed for risk stratification in unselected low-risk cohorts, although it is useful also in surgical patients, as supported by the high sensitivity found in the present study, which is similar to that found in a recent multicenter study (45).

A few limitations of the study also need to be addressed. First, the level of US experience differed between the two investigators before initiation of the study, but SWE agreement did not depend on the educational level of the observers, as recently reported (28), and we found no learning curve during the inclusion period. Second, the proportion of nodules harboring microcalcifications was high in the present study compared with other studies of thyroid US, which may rely on the fact that our patients constitute a selected cohort with an a priori higher risk of thyroid malignancy. Though we cannot exclude that the so-called comet-tail phenomenon were misclassified as microcalcifications in some cases.

The vast majority of the initial studies evaluating thyroid SWE were encouraging, but studies have emerged recently showing more negative outcomes $(32,33)$. Thus, the influence of publication bias in the early era cannot be excluded. According to the present and recent studies $(32,33)$ - and considering the huge variations in design and methodology in previous studies as well as the low agreement of SWE (28) - we find it highly questionable whether the present technology of SWE has any value in the diagnostic management of patients with thyroid nodules. The most important explanation for this may be that the elasticity of benign and malignant nodules de facto shows huge overlap. It may be true that malignant nodules are more firm than benign ones on a group level, but the elasticity of the nodule has very little, if any, predictive value in the individual patient. This conclusion gains support by the suboptimal ability to discriminate malignant from benign thyroid nodules, as reported in several previous studies evaluating this technology https://ec.bioscientifica.com https://doi.org/10.1530/EC-19-0324 (c) 2019 The authors Published by Bioscientifica Ltd
This work is licensed under a Creative Commons Attribution-NonCommercial-NoDerivatives 4.0 Internationab ticense.ifica com at $04 / 26 / 2023$ 01:15:34PM 
$(13,15,21,23,26)$. Beyond these biological limitations, it is crucial that the SWE acquisition process and other methodological issues are standardized.

Thyroid elastography was at its introduction met with great enthusiasm, but it should be emphasized that US risk stratification of thyroid nodules still rely on grayscale features. Accordingly, international US guidelines $(3,11$, 46) have been reluctant to include thyroid elastography in the risk score assessment of thyroid nodules.

\section{Declaration of interest}

The authors declare that there is no conflict of interest that could be perceived as prejudicing the impartiality of the research reported.

\section{Funding}

The project was supported financially by Fonden af 17-12-1981 (Copenhagen, Denmark) (grant for K Z S), Aarhus University (Aarhus, Denmark) (grant for K Z S) and by the Central Denmark Region (Denmark) (funding for equipment).

\section{Acknowledgements}

Peer Christiansen (Department of Plastic and Breast Surgery, Aarhus University Hospital, Demark) has participated in the initiation and planning of the study, and Bo Martin Bibby (Department of Biostatistics, Aarhus University, Denmark) has provided statistical consultancy to the project.

\section{References}

1 Hegedus L. Clinical practice. The thyroid nodule. New England Journal of Medicine 2004351 1764-1771. (https://doi.org/10.1056/ NEJMcp031436)

2 Campanella P, Ianni F, Rota CA, Corsello SM \& Pontecorvi A. Quantification of cancer risk of each clinical and ultrasonographic suspicious feature of thyroid nodules: a systematic review and metaanalysis. European Journal of Endocrinology 2014170 R203-R211. (https://doi.org/10.1530/EJE-13-0995)

3 Haugen BR, Alexander EK, Bible KC, Doherty GM, Mandel SJ, Nikiforov YE, Pacini F, Randolph GW, Sawka AM, Schlumberger M et al. 2015 American Thyroid Association management guidelines for adult patients with thyroid nodules and differentiated thyroid cancer: the American Thyroid Association Guidelines task force on thyroid nodules and differentiated thyroid cancer. Thyroid 201626 1-133. (https://doi.org/10.1089/thy.2015.0020)

4 Monpeyssen $\mathrm{H}$, Tramalloni J, Poiree S, Helenon O \& Correas JM. Elastography of the thyroid. Diagnostic and Interventional Imaging 201394 535-544. (https://doi.org/10.1016/j.diii.2013.01.023)

5 Park JY, Lee HJ, Jang HW, Kim HK, Yi JH, Lee W \& Kim SH. A proposal for a thyroid imaging reporting and data system for ultrasound features of thyroid carcinoma. Thyroid $2009191257-$ 1264. (https://doi.org/10.1089/thy.2008.0021)

6 Horvath E, Majlis S, Rossi R, Franco C, Niedmann JP, Castro A \& Dominguez M. An ultrasonogram reporting system for thyroid nodules stratifying cancer risk for clinical management. Journal of Clinical Endocrinology and Metabolism 200994 1748-1751. (https:// doi.org/10.1210/jc.2008-1724)

7 Kwak JY, Jung I, Baek JH, Baek SM, Choi N, Choi YJ, Jung SL, Kim EK, Kim JA, Kim JH, et al. Image reporting and characterization system for ultrasound features of thyroid nodules: multicentric Korean retrospective study. Korean Journal of Radiology 201314 110-117. (https://doi.org/10.3348/kjr.2013.14.1.110)

8 Russ G, Royer B, Bigorgne C, Rouxel A, Bienvenu-Perrard M \& Leenhardt L. Prospective evaluation of thyroid imaging reporting and data system on 4550 nodules with and without elastography. European Journal of Endocrinology 2013168 649-655. (https://doi. org/10.1530/EJE-12-0936)

9 Kim EK, Park CS, Chung WY, Oh KK, Kim DI, Lee JT \& Yoo HS New sonographic criteria for recommending fine-needle aspiration biopsy of nonpalpable solid nodules of the thyroid. American Journal of Roentgenology 2002178 687-691. (https://doi.org/10.2214/ ajr.178.3.1780687)

10 Ito Y, Amino N, Yokozawa T, Ota H, Ohshita M, Murata N, Morita S, Kobayashi K \& Miyauchi A. Ultrasonographic evaluation of thyroid nodules in 900 patients: comparison among ultrasonographic, cytological, and histological findings. Thyroid 200717 1269-1276. (https://doi.org/10.1089/thy.2007.0014)

11 Russ G, Bonnema SJ, Erdogan MF, Durante C, Ngu R \& Leenhardt L. European Thyroid Association Guidelines for ultrasound malignancy risk stratification of thyroid nodules in adults: the EU-TIRADS. European Thyroid Journal 20176 225-237. (https://doi.org/10.1159/000478927)

12 Gharib H, Papini E, Paschke R, Duick DS, Valcavi R, Hegedus L, Vitti P \& American Association of Clinical Endocrinologists. American Association of Clinical Endocrinologists, Associazione Medici Endocrinologi, and European Thyroid Association medical guidelines for clinical practice for the diagnosis and management of thyroid nodules. Journal of Endocrinological Investigation 201033 1-50. (https://doi.org/10.1007/BF03346541)

13 Liu B, Liang J, Zheng Y, Xie X, Huang G, Zhou L, Wang W \& Lu M. Two-dimensional shear wave elastography as promising diagnostic tool for predicting malignant thyroid nodules: a prospective singlecentre experience. European Radiology 201525 624-634. (https://doi. org/10.1007/s00330-014-3455-8)

14 Park AY, Son EJ, Han K, Youk JH, Kim JA \& Park CS. Shear wave elastography of thyroid nodules for the prediction of malignancy in a large scale study. European Journal of Radiology 201584 407-412. (https://doi.org/10.1016/j.ejrad.2014.11.019)

15 Liu Z, Jing H, Han X, Shao H, Sun YX, Wang QC \& Cheng W. Shear wave elastography combined with the thyroid imaging reporting and data system for malignancy risk stratification in thyroid nodules. Oncotarget 20178 43406-43416. (https://doi.org/10.18632/ oncotarget.15018)

16 Chen M, Zhang KQ, Xu YF, Zhang SM, Cao Y \& Sun WQ. Shear wave elastography and contrast-enhanced ultrasonography in the diagnosis of thyroid malignant nodules. Molecular and Clinical Oncology 20165 724-730. (https://doi.org/10.3892/mco.2016.1053)

17 Cosgrove D, Barr R, Bojunga J, Cantisani V, Chammas MC, Dighe M, Vinayak S, Xu JM \& Dietrich CF. WFUMB guidelines and recommendations on the clinical use of ultrasound elastography: part 4. Thyroid. Ultrasound in Medicine and Biology 201743 4-26. (https://doi.org/10.1016/j.ultrasmedbio.2016.06.022)

18 Bamber J, Cosgrove D, Dietrich CF, Fromageau J, Bojunga J, Calliada F, Cantisani V, Correas JM, D'Onofrio M, Drakonaki EE, et al. EFSUMB guidelines and recommendations on the clinical use of ultrasound elastography. Part 1: basic principles and technology. Ultraschall in der Medizin 201334 169-184. (https://doi. org/10.1055/s-0033-1335205)

19 Sebag F, Vaillant-Lombard J, Berbis J, Griset V, Henry JF, Petit P \& Oliver C. Shear wave elastography: a new ultrasound imaging mode for the differential diagnosis of benign and malignant thyroid nodules. Journal of Clinical Endocrinology and Metabolism 201095 5281-5288. (https://doi.org/10.1210/jc.2010-0766)

20 Veyrieres JB, Albarel F, Lombard JV, Berbis J, Sebag F, Oliver C \& Petit P. A threshold value in Shear Wave elastography to rule out malignant thyroid nodules: a reality? European Journal of Radiology 201281 3965-3972. (https://doi.org/10.1016/j.ejrad.2012.09.002) 
21 Kim H, Kim JA, Son EJ \& Youk JH. Quantitative assessment of shear-wave ultrasound elastography in thyroid nodules: diagnostic performance for predicting malignancy. European Radiology 201323 2532-2537. (https://doi.org/10.1007/s00330-013-2847-5)

22 Szczepanek-Parulska E, Wolinski K, Stangierski A, Gurgul E, Biczysko M, Majewski P, Rewaj-Losyk M \& Ruchala M. Comparison of diagnostic value of conventional ultrasonography and shear wave elastography in the prediction of thyroid lesions malignancy. PLoS ONE 20138 e81532. (https://doi.org/10.1371/journal.pone.0081532)

23 Bhatia KS, Tong CS, Cho CC, Yuen EH, Lee YY \& Ahuja AT. Shear wave elastography of thyroid nodules in routine clinical practice: preliminary observations and utility for detecting malignancy. European Radiology 201222 2397-2406. (https://doi.org/10.1007/ s00330-012-2495-1)

24 Duan SB, Yu J, Li X, Han ZY, Zhai HY \& Liang P. Diagnostic value of two-dimensional shear wave elastography in papillary thyroid microcarcinoma. OncoTargets and Therapy 20169 1311-1317. (https://doi.org/10.2147/OTT.S98583)

25 He YP, Xu HX, Wang D, Li XL, Ren WW, Zhao CK, Bo XW, Liu BJ $\&$ Yue WW. First experience of comparisons between two different shear wave speed imaging systems in differentiating malignant from benign thyroid nodules. Clinical Hemorheology and Microcirculation 201765 349-361. (https://doi.org/10.3233/CH-16197)

26 Dobruch-Sobczak K, Zalewska EB, Guminska A, Slapa RZ, Mlosek K, Wareluk P, Jakubowski W \& Dedecjus M. Diagnostic performance of shear wave elastography parameters alone and in combination with conventional B-mode ultrasound parameters for the characterization of thyroid nodules: a prospective, dual-center study. Ultrasound in Medicine and Biology 201642 2803-2811. (https://doi.org/10.1016/j. ultrasmedbio.2016.07.010)

27 Cibas ES, Ali SZ \& NCI Thyroid FNA State of the Science Conference. The Bethesda system for reporting thyroid cytopathology. American Journal of Clinical Pathology 2009132 658-665. (https://doi. org/10.1309/AJCPPHLWMI3JV4LA)

28 Swan KZ, Nielsen VE, Bibby BM \& Bonnema SJ. Is the reproducibility of shear wave elastography of thyroid nodules high enough for clinical use? A methodological study. Clinical Endocrinology $2017 \mathbf{8 6}$ 606-613. (https://doi.org/10.1111/cen.13295)

29 Bhatia K, Tong CS, Cho CC, Yuen EH, Lee J \& Ahuja AT. Reliability of shear wave ultrasound elastography for neck lesions identified in routine clinical practice. Ultraschall in der Medizin 201233 463-468. (https://doi.org/10.1055/s-0032-1325330)

30 Rago T, Scutari M, Santini F, Loiacono V, Piaggi P, Di Coscio G, Basolo F, Berti P, Pinchera A \& Vitti P. Real-time elastosonography: useful tool for refining the presurgical diagnosis in thyroid nodules with indeterminate or nondiagnostic cytology. Journal of Clinical Endocrinology and Metabolism 201095 5274-5280. (https://doi. org/10.1210/jc.2010-0901)

31 Szczepanek-Parulska E, Wolinski K, Stangierski A, Gurgul E \& Ruchala M. Biochemical and ultrasonographic parameters influencing thyroid nodules elasticity. Endocrine 2014 47 519-527. (https://doi.org/10.1007/s12020-014-0197-y)

32 Bardet S, Ciappuccini R, Pellot-Barakat C, Monpeyssen H, Michels JJ, Tissier F, Blanchard D, Menegaux F, de Raucourt D, Lefort M, et al. Shear wave elastography in thyroid nodules with indeterminate cytology: results of a prospective bicentric study. Thyroid 201727 1441-1449. (https://doi.org/10.1089/thy.2017.0293)

33 Nattabi HA, Sharif NM, Yahya N, Ahmad R, Mohamad M, Zaki FM \& Yusoff AN. Is diagnostic performance of quantitative 2D-shear wave elastography optimal for clinical classification of benign and malignant thyroid nodules? A systematic review and meta-analysis. Academic Radiology 2017 [epub]. (https://doi.org/10.1016/j.acra.2017.09.002)

34 Tian W, Hao S, Gao B, Jiang Y, Zhang X, Zhang S, Guo L, Yan J $\&$ Luo D. Comparing the diagnostic accuracy of RTE and SWE in differentiating malignant thyroid nodules from benign ones: a metaanalysis. Cellular Physiology and Biochemistry 201639 2451-2463. (https://doi.org/10.1159/000452513)

35 Zhang B, Ma X, Wu N, Liu L, Liu X, Zhang J, Yang J \& Niu T. Shear wave elastography for differentiation of benign and malignant thyroid nodules: a meta-analysis. Journal of Ultrasound in Medicine 201332 2163-2169. (https://doi.org/10.7863/ultra.32.12.2163)

36 Lin P, Chen M, Liu B, Wang S \& Li X. Diagnostic performance of shear wave elastography in the identification of malignant thyroid nodules: a meta-analysis. European Radiology 201424 2729-2738. (https://doi.org/10.1007/s00330-014-3320-9)

37 Bhatia KS, Lam AC, Pang SW, Wang D \& Ahuja AT. Feasibility study of texture analysis using ultrasound shear wave elastography to predict malignancy in thyroid nodules. Ultrasound in Medicine and Biology 201642 1671-1680. (https://doi.org/10.1016/j ultrasmedbio.2016.01.013)

38 Fukuhara T, Matsuda E, Endo Y, Takenobu M, Izawa S, Fujiwara K \& Kitano $\mathrm{H}$. Correlation between quantitative shear wave elastography and pathologic structures of thyroid lesions. Ultrasound in Medicine and Biology 201541 2326-2332. (https://doi.org/10.1016/j. ultrasmedbio.2015.05.001)

39 Lyshchik A, Higashi T, Asato R, Tanaka S, Ito J, Hiraoka M, Brill AB, Saga T \& Togashi K. Elastic moduli of thyroid tissues under compression. Ultrasonic Imaging 200527 101-110. (https://doi. org/10.1177/016173460502700204)

40 Lam AC, Pang SW, Ahuja AT \& Bhatia KS. The influence of precompression on elasticity of thyroid nodules estimated by ultrasound shear wave elastography. European Radiology 201626 2845-2852. (https://doi.org/10.1007/s00330-015-4108-2)

41 Shiina T, Nightingale KR, Palmeri ML, Hall TJ, Bamber JC, Barr RG, Castera L, Choi BI, Chou YH, Cosgrove D, et al. WFUMB guidelines and recommendations for clinical use of ultrasound elastography: part 1: basic principles and terminology. Ultrasound in Medicine and Biology 201541 1126-1147. (https://doi.org/10.1016/j. ultrasmedbio.2015.03.009)

42 Xue Y, Yao S, Li X \& Zhang H. Value of shear wave elastography in discriminating malignant and benign breast lesions: a metaanalysis. Medicine 201796 e7412. (https://doi.org/10.1097/ MD.0000000000007412)

43 Woo S, Suh CH, Kim SY, Cho JY \& Kim SH. Shear-wave elastography for detection of prostate cancer: a systematic review and diagnostic meta-analysis. American Journal of Roentgenology 2017209 806-814. (https://doi.org/10.2214/AJR.17.18056)

44 Ertekin E, Turan OD \& Tuncyurek O. Is shear wave elastography relevant in the diagnosis of polycystic ovarian syndrome? Medical Ultrasonography 201921 158-162. (https://doi.org/10.11152/mu-1849)

45 Trimboli P, Ngu R, Royer B, Giovanella L, Bigorgne C, Simo R, Carroll P \& Russ G. A multicentre validation study for the EU-TIRADS using histological diagnosis as a gold standard. Clinical Endocrinology 201991 340-347. (https://doi.org/10.1111/cen.13997)

46 Grant EG, Tessler FN, Hoang JK, Langer JE, Beland MD, Berland LL, Cronan JJ, Desser TS, Frates MC, Hamper UM, et al. Thyroid ultrasound reporting lexicon: white paper of the ACR thyroid imaging, reporting and data system (TIRADS) committee. Journal of the American College of Radiology 201512 1272-1279. (https://doi. org/10.1016/j.jacr.2015.07.011) https://ec.bioscientifica.com https://doi.org/10.1530/EC-19-0324 (c) 2019 The authors Published by Bioscientifica Ltd
Received in final form 2 July 2019

Accepted 24 July 2019

Accepted Preprint published online 24 July 2019 